\title{
Laryngeal Precancerous Condition
}

National Cancer Institute

\section{Source}

National Cancer Institute. Laryngeal Precancerous Condition. NCI Thesaurus. Code C7411.

A premalignant pathologic process that affects the epithelial cells of the laryngeal mucosa. 